\title{
RESTAURAÇÃO DA IGREJA NOSSA SENHORA DO CARMO DA ANTIGA SÉ: DISPUTA DE MEMÓRIAS E POLISSEMIA DO BEM PATRIMONIAL ${ }^{1}$
}

\author{
Juliana Lages Sarinho*
}

\begin{abstract}
Resumo: O trabalho examina o processo de construção de memórias relacionadas ao bem patrimonial, a partir do estudo de caso da restauração da Igreja Nossa Senhora do Carmo da antiga Sé, realizada para as comemorações do bicentenário de chegada da Família Real ao Brasil, organizada pela Prefeitura da cidade do Rio de Janeiro em 2008. Mediante a realização de entrevistas semi-diretivas com atores sociais ligados à igreja e aos órgãos responsáveis pelas obras de restauração, além do recurso à documentação gerada para e em função das obras, foram apontadas as escolhas, conflitos e negociações em jogo no planejamento e execução do projeto. Pôde-se constatar ainda, na análise do processo de restauração, a percepção polissêmica desse bem patrimonial, na medida em que esteve sujeito à introdução de novos usos e significados ligados a práticas turísticas e museais que acompanham sua recuperação arquitetônica.
\end{abstract}

Palavras-chave: Patrimônio. Memória. Rio de Janeiro. Igreja Nossa Senhora do Carmo da Antiga Sé.

Abstract: This work has the purpose of investigating the process of construction of memories related with the historical heritage. Such investigation was based on the case study of the restoration of the church Nossa Senhora do Carmo da Antiga Sé carried on by Rio de Janeiro City Hall in 2008 due to the celebration of 200 Years of the Portuguese Royal Family arrival in Brazil. The choices made, the conflicts and the negotiations regarding the planning and execution of the restoration project are pointed out by the interviews with social actors in connection with the church, and entities responsible for the restoration as well as by the access to the material and documentation originated by and produced for the restoration process. By the analyses of the process of restoration, it is also

* Arquiteta, Mestre em Bens Culturais e Projetos Sociais pelo Centro de Pesquisa e Documentação de História Contemporânea do Brasil (CPDOC) da Fundação Getulio Vargas. E-mail: jsarinho@hotmail.com 
noted that the church itself gives rise to different perceptions as consequence of it being subject to new uses and meanings, which are connected to museum and tourist practices that resulted from its architecture restoration.

Keywords: Heritage. Memory. Rio de Janeiro. Church "Nossa Senhora do Carmo da Antiga Sé”.

\section{O GOVERNO DO RIO DE JANEIRO SE PREPARA PARA RELEMBRAR}

Em novembro de 2004, o então prefeito do Rio de Janeiro, César Maia, divulgou oficialmente sua intenção de fazer das comemorações do bicentenário um evento de importância dentro da cidade. As festividades relacionadas à chegada da Família Real estavam previstas para começar em 2005, já em referência ao ano de 1805, e assim, se sucederiam nos anos de 2006, 2007, culminando em 2008.

$\mathrm{O}$ ano do bicentenário suscitou uma série de eventos que lembravam o acontecimento da vinda de D. João VI para as terras da colônia e todas as transformações na cidade daí decorrentes. A Comissão para as Comemorações do Bicentenário da Chegada de D. João ao Rio de Janeiro, criada no mesmo ano pela Prefeitura - e cuja criação dá o tom da importância das festividades para o poder público - foi a instância encarregada de coordenar os diversos eventos que se seguiram, e indicar a maneira como deveriam ser executados. Ao longo de quatro anos o período monárquico, tanto em Portugal quanto depois de sua transferência para o Brasil, foi sistematicamente encenado e relembrado. Em setembro de 2006, através de um convênio ${ }^{2}$ realizado entre a Prefeitura do Rio de Janeiro e a Fundação Roberto Marinho, iniciaram-se as obras que pretendiam, por fim, restaurar as características arquitetônicas da igreja, ao tempo em que esta era palco dos mais importantes eventos da Corte portuguesa. E assim, no dia 8 de março de 2008 uma missa inaugural devolveu esse exemplar da arquitetura sacra colonial restaurada à cidade e à sua população.

Percebe-se nos planos do governo municipal o intuito de criar uma ponte simbólica entre o mandato que se iniciava na Prefeitura e a trajetória histórica que transformou a cidade do Rio de Janeiro na capital do império português. O decreto de criação da Comissão, expedido logo após a reeleição do prefeito, reflete de alguma maneira a intenção do poder público em reforçar uma identidade carioca vinculada à memória monárquica. Interessante perceber a apreensão de um determinado momento histórico pelo poder público, e analisar 
como seu representante se preocupa em construir, ao longo do mandato, um repertório simbólico que se vale de fatos históricos relevantes e verificáveis para interpelar afetivamente uma população não necessariamente identificada com esse passado.

Nada há de ingênuo na reconstrução de pontes entre o passado da cidade e sua contemporaneidade. Segundo Michael Pollak ${ }^{3}$, a operação envolve o trabalho de "enquadramento" de uma memória que, para além da memória nacional, apela a um recorte específico dentro de todo um espaço amostral histórico, de onde provêm os acontecimentos eleitos e aqueles colocados em segundo plano. Esse processo de escolha de determinada memória ajuda a construir no imaginário coletivo um quadro de referências que servirá como ferramenta na construção do sentimento de pertencimento e de diferenciação entre grupos sociais.

A análise do processo de restauração da Igreja Nossa Senhora do Carmo da Antiga Sé nos dá elementos para discutir mais aprofundadamente a maneira como os atores sociais se relacionam com o enquadramento institucional da memória. A construção simbólica do bem patrimonial, através do confronto e da negociação entre a memória institucional, gerada e propagada pelo poder público, e as memórias particulares dos agentes sociais, se configuram, assim, no objeto deste trabalho.

\section{VIABILIZANDO O PROCESSO DE RESTAURAÇÃO: CONTRATO ENTRE A PREFEITURA DO RIO DE JANEIRO E FUNDAÇÃO ROBERTO MARINHO}

Rememorar intensamente fatos históricos ligados ao passado monárquico do Rio de Janeiro talvez seja uma tentativa de dar à cidade, que tem hoje a sua imagem muito ligada à violência, um outro ponto de vista sobre si mesma, um enfoque mais positivo. Este pode ser o legado que esta administração pretendia deixar: um olhar retrospectivo, que privilegia o papel central desempenhado pela cidade na história do país. Cidade-capital, que abrigou o rei e sua corte e que ainda hoje possui evidências deste passado espalhadas pela área urbana na forma de monumentos, ruas e construções.

Dentro desse conjunto de objetivos foi criada, em 2006, a Secretaria Extraordinária de Promoção, Defesa, Desenvolvimento e Revitalização do Patrimônio e da Memória Histórico-Cultural da Cidade do Rio de Janeiro SEDREPAHC. Esta secretaria passou a tratar com exclusividade da política pública de proteção e conservação do patrimônio cultural, tornando-se o órgão responsável por todo o planejamento, coordenação, desenvolvimento, aprovação e fiscalização do patrimônio cultural do município do Rio de 
Janeiro. Sua criação integra um movimento de centralização das ações relativas ao patrimônio histórico e artístico do município - o que, segundo a própria definição encontrada no site da prefeitura, visava a ampliar "as formas de promoção e defesa deste patrimônio e d[ar] maior agilidade à execução de ações municipais em prol da sua preservação". ${ }^{4}$ Foi através desse órgão responsável pela comemoração do bicentenário que o contrato entre Prefeitura do Rio de Janeiro e Fundação Roberto Marinho foi firmado, tendo início o processo de restauração da Igreja Nossa Senhora do Carmo da antiga Sé. ${ }^{5}$

Mas será que a memória histórica monárquica teve ressonância ${ }^{6}$ junto à sociedade carioca? Com essa pergunta em mente fui a campo, realizando entrevistas temáticas semi-diretivas com diferentes atores envolvidos na restauração. ${ }^{7}$ Minha intenção era documentar o processo de escolha deste bem como monumento símbolo da história política do Rio de Janeiro, interrogando também as memórias e polissemias que com ele se relacionam.

Reginaldo Gonçalves dos Santos, apropriando-se do conceito de ressonância formulado por Stephen Greenblatt, ressalta a necessidade de o bem cultural ter seu significado reconhecido para se perpetuar como simbolicamente representativo. ${ }^{8}$ Outra questão é o objetivo da restauração e as diferentes (por vezes conflitantes) concepções político-culturais, que, segundo Nestor García Canclini ${ }^{9}$, orientam esse trabalho. A preocupação com o auto-sustento da igreja, mediante a inclusão de usos que promovam sua inserção nos roteiros turísticos e que viabilizem a atração de um público pagante para o espetáculo de "Som e Luz", dá indícios da preocupação econômica envolvida no processo de restauração. Ao transformar símbolos em produtos a serem consumidos, ainda que sem objetivar a geração de lucro, o caso da Igreja Nossa Senhora do Carmo coloca em evidência a complexidade das relações entre mercado e cultura, que não devem ser tratadas de forma estanque. Durante o processo de entrevistas, pude constar que a inclusão dos novos usos com o intuito de gerar fontes de renda para a igreja, mostrou-se um processo por vezes difícil, o que analisarei com maior atenção mais adiante.

Ao refletir sobre as escolhas técnicas envolvidas no processo de restauração, e a forma com que este bem seria reinserido, com novos usos, ao cotidiano da cidade, pude verificar quais memórias sedimentavam o pertencimento dos atores àquele local e como foi o transcorrer do trabalho que culminou na reinauguração da igreja, e que continua ecoando até hoje naquele espaço. $\mathrm{O}$ contrato entre a prefeitura e a Fundação Roberto Marinho constituti a oficialização e início desse processo, cuja análise requer um olhar atento sobre a polissemia e disputas envolvidas na certificação social dos bens patrimonializados. É o começo de um trabalho que vai além das obras arquitetônicas de restauração, configurando-se em uma transformação simbólica ritualizada: a inauguração da igreja restaurada reforça sua condição 
de, segundo Pierre Nora, "lugar de memória" 10 carioca, lugar que remete à presença da Corte no Rio de Janeiro; à sua condição de capital do Brasil colônia e berço da nacionalidade.

Para Nora, diferentemente da memória, ancorada na experiência cotidiana, a História é a tentativa de representar no presente, de maneira incompleta, um passado que não existe mais. Está ligada ao discurso crítico, de natureza intelectual, que busca uma universalidade capaz de representar a todos e, ao mesmo tempo, a ninguém. "A memória é um absoluto e a história só conhece o relativo". ${ }^{1 "}$ Esse é um ponto de partida para pensarmos o processo de restauração. Não podemos ignorar que o esforço concentrado para construir "lugares de memória" é uma maneira de evidenciar uma história eleita que se legitima a partir da própria evocação. Seria então legítimo perguntar se todo lugar de memória não evoca, à sua própria revelia, o conflito entre uma memória nacional unificadora e contra-memórias de grupo. Afinal, aquela não é única, e nem deve, a priori, ser pensada como a mais representativa daquele espaço ou grupo. Ela é mais um elemento do discurso que vem ratificar valores e personagens que se quer ver em destaque. Mas a memória é gerada à revelia do racionalmente planejado. O aparecimento, assim como os usos e significados da memória não são controláveis; eles surgem na dinâmica social e pressupor sua inexistência pode ser uma maneira de ignorar os discursos que estão à margem do que se quer legitimar.

Sem incorrer em oposições estanques, mas respeitando a natureza distinta dessas duas práticas sociais, o pressuposto seguido nesta análise é o de que nos bens patrimoniais restaurados coabitam a história e a memória - coexistência que se traduz também em "disputa entre memórias". ${ }^{12}$ A restauração é realizada por atores especializados, os quais, valendo-se de dados históricos, traçam um passado cronologicamente coerente, de onde serão eleitos determinados elementos que se destacarão. Ao final do processo, conseguimos fazer uma leitura do bem e enxergamos sua trajetória histórica, antes fragmentada e em decomposição, assim como seus vínculos com a nação ou grupo social ao qual remete.

Porém, paralela à história relacionada ao bem, temos as memórias dos grupos que com ele se relacionam de maneira diversificada. Se o objeto em questão era apropriado por atores sociais que com ele interagiam das mais diferentes formas, temos, a partir do olhar desses atores, memórias que se transmutam, reconfiguram e eventualmente se contrapõem à memória histórica, sem deixar de enfrentar seus próprios conflitos internos. Trata-se da dialética entre a memória institucional, impressa na própria condição estatutária do monumento submetido a políticas de salvaguarda e objeto das obras de restauração, e a memória de grupos que estabelecem uma relação afetiva com 
o templo. Tal relação não se esgota, nem é necessariamente pautada, na noção de "patrimônio", mas articula às dimensões estéticas e históricas privilegiadas pelas concepções que orientam o trabalho de restauração, outras dimensões - por exemplo, religiosas e morais - muitas vezes imprevistas pelos agentes "enquadradores" da memória materializada nos monumentos.

\section{ATORES EM DESTAQUE: SEDREPAHC, MITRA} ARQUIDIOCESANA, IPHAN, INSTITUTO DE ARQUEOLOGIA BRASILEIRA E FUNDAÇÃO ROBERTO MARINHO

O contrato firmado entre a Prefeitura do Rio de Janeiro, na figura da SEDREPAHC, e a Fundação Roberto Marinho teve a cooperação técnica da Mitra Arquidiocesana e a fiscalização do Instituto do Patrimônio Histórico e Artístico Nacional (Iphan). A interação entre esses atores, cada qual com o foco em sua competência, configura um campo de disputa que evidencia o quão complexo é o processo de restauração.

A Prefeitura do Rio de Janeiro tinha como objetivo tornar a Igreja Nossa Senhora do Carmo da antiga Sé o monumento central e mais representativo dentro das comemorações do bicentenário. Para isso, era imprescindível que as obras terminassem na data prevista, 08 de março de 2008, e que além da restauração arquitetônica houvesse sido elaborado todo o conjunto de ações educativas que promoveriam o diálogo deste monumento com o público, contando-lhe a história do Rio de Janeiro sede do império português.

A Mitra Arquidiocesana é o ator que detém o conhecimento sobre os signos e significados religiosos manipulados durante as obras. Aliada à Mitra estava a Sociedade dos Amigos da Antiga Sé (SAMAS), que é personagem ativo na história da igreja, principalmente no que tange às restaurações por que passou nos últimos anos. Essas duas instituições podem ser consideradas os "clientes" mais diretos do projeto, pois são as que estavam mais diretamente ligados à construção antes das obras, e ficariam responsáveis pela manutenção depois da sua reabertura.

A Mitra e a SAMAS foram os atores responsáveis por avaliar o plano de restauração e verificar se as prioridades e usos estipulados estavam de acordo com o dia-a-dia da igreja. Além disso, houve por parte da Mitra a orientação na condução das obras, principalmente quando as escavações do sítio arqueológico começaram, no sentido de manter, dentro daquele espaço, a ordem hierárquica onde o sagrado encontra-se em primeiro lugar. Esses atores privilegiam em suas decisões as características simbólicas da edificação ligadas às práticas ritualísticas, enquanto os demais atores dispensaram à construção um olhar técnico, avaliando suas características arquitetônicas e funcionalidade. Essa 
diversidade de percepções nos dá indícios de como as articulações no campo do patrimônio podem ser complexas, o que torna impossível lê-las apenas de uma forma e sob um viés.

O papel do Iphan durante as obras de restauração foi o de, através de sua $6^{\text {a }}$ Superintendência Regional, aprovar e fiscalizar as obras. Considerando que a Igreja Nossa Senhora do Carmo é um bem tombado em instância federal, todos os serviços propostos deveriam ser previamente analisados, sendo necessário chegar, em conjunto com os demais envolvidos, a um consenso no que tange às diretrizes adotadas. Mariângela Castro e Cristina Lodi no texto A restauração do monumento-símbolo das comemorações dos 200 anos da chegada de D. João e da Família Real ao Rio de janeiro, destacam "o empenho do Iphan nas pesquisas histórica e de evolução da decoração interna, fundamentais para a definição do conceito da restauração da talha rococó". ${ }^{13}$ O Iphan dividiu, junto com a Fundação Roberto Marinho, a responsabilidade técnica pelas obras, coordenando uma equipe que assessorou as ações de arqueologia, história, restauração artística, restauração arquitetônica, sistemas especiais de segurança, estruturas, luminotécnica, etc. ${ }^{14} \mathrm{~A}$ igreja que se encontra aberta ao público hoje é resultado de uma série de debates entre atores situados em diferentes instâncias sobre que história seria contada através das obras de restauração. O que se tem aqui é uma relação de disputa e negociação permanentes, decorrente da intenção de cada grupo de atores em validar sua percepção sobre o bem patrimonial. Suas respectivas funções, no processo de restauração, em que pese serem complementares, geraram embates que tiveram que ser resolvidos para que a obra avançasse e o trabalho finalizasse de maneira coerente e no prazo estipulado.

No caso da SEDREPAHC, esta tinha como objetivo preservar a visão simbólica do poder público sobre a obra. A secretaria era a garantidora de que ao fim do processo a construção espelhasse o esplendor da era joanina, sendo a restauração da Igreja o ponto focal das comemorações. Em sua interação com os demais atores, havia a preocupação em manter a obra no prazo, para que a comemoração fosse iniciada a contento, manter os gastos dentro do orçamento previsto e assegurar que o resultado final refletisse a boa administração e a preocupação da Prefeitura do Rio de Janeiro com e preservação do passado da cidade.

A Prefeitura era a contratante, quem estabelece seus limites e estipula o que gostaria de receber ao final. Portanto era a ela que os demais atores prestavam contas no decorrer das obras: "Eu tinha o tempo todo a SEDREPAHC com a gente e mandando tanto quanto a gente" (Arquiteta Mariângela Castro - Fundação Roberto Marinho).

O Iphan, enquanto órgão fiscalizador, tinha nas mãos a tarefa de avaliar as escolhas técnicas propostas pelos encarregados da obra. Tais escolhas são 
baseadas em pesquisas históricas, arquivísticas e iconográficas da evolução arquitetônica do bem. A partir do entendimento desta evolução, busca-se espelhar no projeto de restauração os elementos mais relevantes dessa história arquitetônica. Porém, quando falamos deste projeto de restauração, estamos na verdade referindo-nos a uma construção que iniciou sua trajetória histórica no século XVI, e que vem sendo modificada e reformada até os dias atuais. Não é tarefa fácil determinar os caminhos a seguir no momento da restauração, pois se trabalha, primordialmente, com o que será lembrado e o que será esquecido. E ter como encargo a avaliação e aprovação dessas escolhas atribui ao Iphan um papel decisivo dentro deste cenário. Ele precisou negociar com os anseios simbólicos do poder público, com as propostas técnicas apresentadas pela Fundação Roberto Marinho e com o olhar de usuário da Mitra e da SAMAS.

Um evento que chama a atenção durante o processo de restauração da Igreja Nossa Senhora do Carmo, e que agregou mais um ator às obras de restauração, foi a descoberta, durante as pesquisas arqueológicas, de construções, utensílios e ossadas que justificaram a construção de um Museu do sítio arqueológico. Este sítio não estava previsto no escopo inicial das obras e sua inclusão acabou por alterar de maneira significativa o projeto arquitetônico, principalmente em relação aos usos dos ambientes. Com essa importante descoberta o Instituto de Arqueologia Brasileira (IAB) se configura em mais um ator que irá buscar, dentro do espaço de disputa estabelecido, dar destaque para a matéria de sua competência. Tanto na entrevista realizada com a arquiteta Mariângela Castro $^{15}$, quanto na entrevista com o Padre Roque ${ }^{16}$, atual pároco da Igreja Nossa Senhora do Carmo, há momentos em que fica clara a dificuldade de compatibilizar demandas tão distintas, dado que cada instituição envolvida possuía um olhar particular sobre os usos e potencialidades da igreja.

\footnotetext{
Nós entendíamos [...] que fazer ali, no meio da capela-mor, uma visita do público, a gente tinha restrições com relação a isso. Mas, isso não era muito claro para todo mundo que estava ali, dos técnicos. Porque os técnicos se empolgam muito, no caso da arqueologia, eles achavam aquilo o mais importante. [...] Então precisou dom Ednei sentar com a gente e ele fez uma explanação muito racional do porque que não podia transformar aquela área da igreja num centro de visitação (Arquiteta Mariângela Castro - Fundação Roberto Marinho).
}

A Fundação Roberto Marinho, que foi escolhida diretamente pela Prefeitura do Rio de Janeiro como coordenadora do projeto, articulava com as mais instâncias - Iphan, Mitra, SAMAS, SEDREPAHC - e ainda era a responsável pela contratação de equipes terceirizadas que iriam planejar e 
executar as obras, conceber e implantar as ações educativas. Seriam então duas frentes de trabalho de naturezas diversas, mas que deveriam dialogar. Apesar de estar à frente do canteiro de obras e ser respeitada por sua trajetória de atuação na conservação do patrimônio cultural brasileiro, suas ações foram avaliadas e afiançadas pela SEDREPAHC. Realizar uma obra de restauração dentro de um orçamento pré-determinado e tendo que cumprir um cronograma rígido já é um desafio, mas o desafio maior, segundo a Mariângela Castro, foi justamente lidar com um grupo de trabalho composto por técnicos tão qualificados quanto os da Fundação Roberto Marinho, e que possuíam legitimidade dentro do processo para dialogar de igual para igual. ${ }^{17}$

Segundo o Padre Roque, a restauração se configurou em um desafio conciliatório para ele e para a Mitra Arquidiocesana. Muitas propostas que levavam em conta questões técnicas ou que eventualmente priorizavam ressaltar o passado arqueológico da construção foram motivo de conflito. Salvaguardar as características simbólicas do templo, preservando o uso litúrgico do espaço, foi o papel principal desempenhado pela Mitra e pela Sociedade de Amigos da antiga Sé. Além disso, era necessário que as obras de restauração levassem em consideração a dinâmica daquele espaço, ocupado por grupos que se religam a ele através da devoção. A relação com o sagrado envolve a produção e transmissão de memórias que divergem da história contada pela restauração, memórias que o mais das vezes se mantêm "subterrâneas", presas aos espaços da informalidade. É para este grupo de atores e suas memórias ligadas à Igreja Nossa Senhora da antiga Sé, que pretendo dispensar um olhar mais atento a partir deste ponto.

\section{ATORES SILENCIADOS: FIÉIS E FUNCIONÁRIOS}

A paróquia de Nossa Senhora do Carmo da antiga Sé conta com alguns grupos que se ocupam de suas atividades: Grupo de Catequese de Adultos, Arquiconfraria Nossa Senhora da Cabeça, Apostolado da Oração, Grupo de Oração pelas Vocações Sacerdotais (OVS), Grupo de Oração Pão da Palavra e Pastoral do Turismo.

Essa igreja, por se localizar no centro da cidade do Rio de Janeiro, possui características que a diferenciam das paróquias localizadas em bairros de uso residencial mais intenso. O centro da cidade concentra hoje uma grande variedade de empresas, instituições e comércio. Porém, esta área é bastante esvaziada com relação ao uso habitacional, recebendo, durante o horário comercial, pessoas que se deslocam para este local e que retornam aos seus lugares de origem após a finalização das suas atividades. Esse movimento pendular torna o centro carioca um local com grande adensamento populacional 
em determinados dias e horários e da mesma maneira o torna vazio, quando a população que ali vivencia seu cotidiano econômico ou profissional volta para o seu local de moradia.

Nas paróquias de bairro as atividades são programadas para atender aos fiéis que moram na localidade onde estas se inserem. São atividades que se concentram nas necessidades específicas do entorno e que, por reunir habitantes de um mesmo bairro, conseguem formatar sua grade de horários e projetos para atendê-los. As paróquias de bairro acabam trabalhando com fiéis que nela irão frequentar as missas, os grupos de catequese, batizar seus filhos e as demais atividades que sedimentam afinidades entre a localidade e a paróquia.

Eu moro em Vila Isabel. A minha paróquia de bairro... Que cada pessoa tem a sua paróquia de bairro. Eu moro em Vila Isabel, então a minha paróquia é Nossa Senhora de Lurdes, que fica a sete minutos da minha casa. É a minha paróquia de bairro. Lá, até esse ano de 2008, eu era a coordenadora da catequese. É minha paróquia de bairro. Mas como eu trabalhava naquela época, eu fui convidada e passei a participar dos encontros aqui (Dona Joana D`Arc Marinho ${ }^{18}$ - Grupo de Oração Pão da Palavra).

E como se posiciona uma paróquia que não pertence a uma localidade com características residenciais? Os usos do sítio onde a Igreja Nossa Senhora do Carmo está inserida afetam-na diretamente, pois suas atividades têm que se adequar à realidade do entorno. Durante as entrevistas que realizei, a igreja foi chamada de "paróquia de trânsito", termo que remete ao movimento pendular dos fiéis que estão em deslocamento e que, em geral, reservam para sua prática religiosa dois momentos do dia: o momento antes de iniciar seu turno de trabalho e o horário de almoço. Além de lidar com a mobilidade dos frequentadores, a paróquia de trânsito divide com a paróquia de bairro a fidelidade dos paroquianos. Portanto, para os atores que estão presentes no cotidiano da igreja, ela possui algum diferencial que faz com que a ida a esse templo seja importante, criando laços que vão além da proximidade física.

[...] Essas que estão há muito tempo, elas eram pessoas que freqüentavam o centro da cidade trabalhando; se aposentaram e tudo mais, mas continuam indo lá. Então é mais uma igreja por afinidade amorosa, o amor à igreja ali do centro, do que realmente por obrigação de estar ali. Então elas vêm, freqüentam determinados dias, alguns grupos, 
não é, são seis pastorais, e dá movimento para muita coisa (Padre Roque - Pároco da Igreja Nossa Senhora do Carmo da antiga Sé).

A vivência dessa paróquia de trânsito pode ser melhor entendida se analisarmos dois grupos que estão na rotina da igreja há muito tempo, e cujos integrantes são representativos das memórias geradas na interação com esse bem patrimonial: a "Confraria de Nossa Senhora da Cabeça" e o "Grupo de Oração Pão da Palavra”. Esses dois grupos foram identificados, tanto pelos fiéis quanto pelo pároco da igreja, como sendo os que reúnem os integrantes mais ativos e engajados no dia-a-dia da paróquia.

A Confraria de Nossa Senhora da Cabeça se reúne todas as quartas-feiras às 9 horas da manhã para uma missa que reverencia a imagem de Nossa Senhora da Cabeça, localizada em um dos altares laterais da nave. Essa confraria está presente na Igreja Nossa Senhora do Carmo desde 1912 e se configura no grupo mais antigo de frequentadores. Os entrevistados ligados à Confraria relataram graças obtidas por intermédio da santa, indicando que a gratidão pode ser um elo importante na coesão deste grupo.

Os médicos falaram para meus filhos que eu ia ficar louca e cega, então eu fiz um voto a Jesus e a Nossa Senhora da Cabeça que, se eu não ficasse cega nem louca, ia trabalhar para onde tivesse uma imagem de Nossa Senhora da Cabeça. Que nessa ocasião não tinha ainda a igreja, na Penha, de Nossa Senhora da Cabeça, só tinha essa imagem aqui. Então eu fiquei vindo toda quarta-feira. Aí me botaram como a presidente da Confraria. Três vezes já, que eu fui nomeada presidente. É a terceira vez (Dona Ondina ${ }^{19}$ - Confraria de Nossa Senhora da Cabeça).

O Grupo de Oração Pão da Palavra foi fundado no dia 30 de setembro de 1978 e promove, de segunda a sexta-feira, às 12:15 horas, um encontro para os fiéis que, em seu horário de almoço, buscam um momento litúrgico. Além disso, organiza visitas, festas e doações a hospitais e asilos. Nas paróquias de bairro, os grupos de oração têm duração de duas horas e os encontros acontecem uma vez por semana. No caso da Igreja Nossa Senhora do Carmo, o grupo se reúne de segunda-feira a quinta-feira durante meia hora e na sexta-feira celebrase a missa. Como existe o deslocamento, os integrantes do grupo se revezam para realizar a pregação diária e atender aos que entram na igreja. Esse grupo demonstra claramente a vocação da igreja para atender à população que busca a paróquia em um horário pouco convencional. 
Na hora do almoço, justamente. É. Porque o normal, um grupo de oração, ele leva duas horas, é uma vez por semana, em qualquer igreja. Mas como aqui é no centro da cidade, não é, então nós acabamos fazendo... cumprindo o que o grupo de oração pede: duas horas. Porque é meia hora por dia. Aí nós fechamos, na sexta-feira, com a santa missa (Dona Sandra ${ }^{20}$ - Grupo de Oração Pão da Palavra).

Existe ainda um grupo de atores sociais que está intimamente ligado à igreja, e que com ela estabelece uma relação que não passa, necessariamente, pela religiosidade. Esse grupo, composto pelos funcionários ${ }^{21}$ contratados pela paróquia, desempenha papel fundamental no cotidiano operacional do espaço e estabelece com ele uma relação diferenciada.

Tanto os fiéis quanto os funcionários ofereceram informações valiosas sobre o processo de restauração da igreja. O estado anterior do templo, a forma como transcorreram as obras e a avaliação final destes grupos trouxeram elementos que não estão claros nos registros oficiais daquele processo. Nas pesquisas realizadas sobre a restauração o foco usual recai nas questões técnicas enfrentadas e na atuação dos atores oficiais, que neste caso são a Prefeitura do Rio de Janeiro, a Fundação Roberto Marinho, o Iphan, a Mitra Arquidiocesana e a SAMAS. Porém, analisando as entrevistas pode-se perceber que a relação dessas instâncias com os usuários da igreja foi mediada pelo pároco, que tratava de conciliar o que fora decidido nas reuniões de trabalho com a manutenção das atividades de funcionários e fiéis.

Portanto, o que podemos perceber é a coexistência de dois grupos durante o processo de restauração: o grupo que edifica, e o que habita. ${ }^{22}$ Tal coexistência está relacionada à persistência com que uma construção de caráter religioso mantém seus atributos simbólicos mais elementares, mesmo quando musealizada por uma intervenção de caráter estetizante ou historicista. Ou seja, sobre uma construção deste tipo, como é o caso da Igreja Nossa Senhora do Carmo, sempre recaíram olhares que lhe atribuíram significados outros, além dos diversos representados em sua restauração. As experiências que levam e mantêm os fiéis ligados àquele espaço imprimem uma carga simbólica significativa ao processo de restauração, pois é na singularidade destes olhares que encontramos o discurso oculto, porém vivo e dinâmico, do que a igreja, enquanto bem, representa.

Diante desse quadro, no qual se apresentam então dois blocos de atores sociais que atuaram durante as obras de restauração da igreja, identifiquei que seria interessante e rico para este estudo dar voz aos que, pela própria dinâmica de documentação, divulgação e veiculação na mídia deste evento, não tiveram sua fala documentada e posta em evidência. Ou seja, o discurso dos fiéis, dos 
funcionários e do pároco da igreja serão parte integrante da análise do processo de restauração deste patrimônio.

Trabalhar com essas memórias, que circulam dentro de um determinado grupo e que não ganharam visibilidade, possibilita ampliar as possibilidades de entendimento do bem patrimonial. Os pontos de conflito e disputas que ocorreram no processo que tomou a igreja como palco, virão à tona na confrontação da memória institucional com essa memória afetiva dos devotos, para a qual chamo a atenção. E devo acrescentar que, para um entendimento mais amplo dos efeitos das obras de restauração sobre o dia-a-dia da paróquia se faz necessária a interlocução com aqueles que ainda permanecem no local e conseguem estabelecer, através da vivência in loco, uma avaliação do antes, durante e hoje.

\section{PLANEJAMENTO DAS AÇÕES DAS OBRAS DE RESTAURAÇÃO}

O curto prazo de dezoito meses para a execução dos trabalhos exigiu dos envolvidos no projeto de restauração um esforço concentrado e planejado. Segundo Mariângela Castro e Cristina Lodi, foi elaborado um plano de trabalho entre as áreas envolvidas no projeto, que serviu de base para a atualização do Plano Diretor de Restauração do Conjunto arquitetônico da Sé, aprovado pelo Iphan. Esse plano era composto pelas seguintes etapas: “(1) pesquisa histórica e elaboração de projetos técnicos; (2) restauração das fachadas laterais - ruas Sete de Setembro, do Carmo e laterais da igreja da Ordem Terceira do Carmo e empenas internas; (3) restauro artístico dos elementos decorativos; (4) restauração arquitetônica; (5) serviços de arqueologia; (6) conservação dos bens móveis (mobiliários, imagens e lustres); (7) implantação de novas instalações hidrosanitárias, elétrica, prevenção contra incêndio e contra intrusão, sistema de proteção contra descarga atmosférica e descida de águas pluviais; (8) ações de educação: capacitação de professores/ Caderno de educação/ exposição e visitas guiadas; (9) espetáculo permanente de Som e Luz". ${ }^{23}$

A área sob intervenção englobou todo o andar térreo, as tribunas e o coro, localizados no primeiro pavimento. Essa intervenção, obviamente, interferiu diretamente no cotidiano da paróquia. Houve, por parte da Fundação Roberto Marinho, um grande investimento no planejamento de cada uma das fases da obra de restauração, assim como na determinação dos limites na dinâmica da igreja. A análise do Caderno de estratégia de ação - cronograma físico detalhando, revela que foi levada em conta a necessidade da permanência de algumas atividades na igreja, e que o cronograma e a maneira como a obra se desenvolveria deveriam ter essa diretriz como norteadora das ações. 
O Grupo de Oração Pão da Palavra continuou a se encontrar diariamente e a Confraria de Nossa Senhora da Cabeça também manteve seus encontros às quartas-feiras. Além dessas atividades relacionadas aos grupos de fiéis, a secretaria e os funcionários da igreja continuaram desempenhando suas funções nos horários regulares. Entretanto, nos relatos dos fiéis, verifica-se que mesmo com o planejamento, as atividades tiveram que se deslocar para a igreja vizinha, a de Nossa Senhora da Ordem Terceira do Carmo, o que trouxe uma série de dificuldades para a manutenção da rotina litúrgica. No discurso dos integrantes do Grupo de Oração Pão da Palavra percebe-se que a mudança de endereço gerou desconforto. Sendo este grupo voltado para o atendimento do público que busca uma mensagem religiosa durante o horário do almoço, a alteração do local da prática fez com que perdessem um número expressivo de frequentadores, que ao buscar a igreja e encontrá-la em obras se desligaram do grupo.

[...] depois, com a restauração, aquele ambiente foi ficando pesado, tudo muito escuro, as pessoas tinham até medo de entrar aqui. Tinham medo, sim, medo, porque era tudo escuro, naquele período que ficou fechada para restauração, então esvaziou-se um pouco. E agora, graças a Deus, está voltando novamente. Alguns por curiosidade, outros porque passam e vêem (Dona Joana D’Arc Marinho - Grupo de Oração Pão da Palavra).

Impacto diferente, mas com igual necessidade de adaptação, sofreu a Confraria Nossa Senhora da Cabeça. Ela também teve seu local de encontro transferido para a Igreja Nossa Senhora da Ordem Terceira do Carmo. Porém, como este grupo composto por devotos de Nossa Senhora da Cabeça é mais coeso, seu deslocamento pôde ser avisado e mesmo diante da precariedade física acarretada pela alteração, os membros não se dispersaram durante as obras.

Interessante notar como, mesmo sendo inviável a permanência dos cultos na nave durante o período das obras, o deslocamento dos fiéis por um curto período de tempo afeta diferentemente os coabitantes da paróquia. Existem características específicas por parte de cada grupo que podem demandar a construção de uma nova rede de relações sociais e de amparo mútuo, passível de esgarçamento mesmo com a curta ausência. No caso do Grupo de Oração Pão da Palavra isso se mostra de maneira clara, pois sua representatividade simbólica se referencia ao local. A periodicidade, a hora e o lugar que este ritual ocupa são elementos chave para sua razão de existir, pois atendem aos atores sociais que de maneira esporádica e incerta buscam a igreja no horário do almoço. A existência da celebração é uma certeza, quem 
irá participar dela, não. Desta maneira, é possível imaginar que uma alteração de endereço, mesmo que para uma igreja ao lado, tenha desestabilizado este grupo, impelido a recosturar sua relações com a comunidade e restabelecer seu pacto simbólico de apoio religioso.

A igreja fica aberta, começa o grupo... agora, como começou, você vai ver, tem umas duas, três pessoas; daqui a pouquinho, as pessoas, que já sabem, vêm do almoço correndo para cá, participam e vão embora. Aí fica uma média de quinze, vinte pessoas (Dona Sandra - Grupo de Oração Pão da Palavra).

\section{PESQUISA HISTÓRICA E ANÁLISE DE DANOS}

A primeira etapa do projeto, antes do início das obras, visou um aprofundamento na pesquisa da história da Igreja Nossa Senhora do Carmo, procurando embasar as decisões de projeto que seriam tomadas a seguir. A pesquisa histórica se configura em uma importante ferramenta a complementar e ajudar nas pesquisas arquitetônicas e arqueológicas acerca do monumento. Os questionamentos que surgem no presente irão se utilizar da pesquisa histórica para lançar um olhar crítico sobre o passado e tentar extrair das fontes primárias e secundárias elementos que nortearão o processo de restauração. É nesta etapa que são reconstruídos os processos históricos dos quais o bem imóvel tomou parte, a evolução da sua estrutura construída e os usos que ali tomaram lugar ao longo do tempo. Somente através de um bom trabalho de reconstrução histórica, o que envolve pesquisa interdisciplinar, é que se pode iniciar o projeto de restauração. Segundo a Carta de Burra"24, "a restauração deve servir para mostrar novos aspectos em relação à significação cultural do bem. Ela se baseia no princípio do respeito ao conjunto de testemunhos disponíveis, sejam materiais, documentais ou outros, e deve parar onde começa a hipótese". Ou seja, a pesquisa histórica, aliada à arquitetônica e arqueológica, é fundamental para que as escolhas técnicas sejam embasadas e que todas as possibilidades dentro do campo representativo-simbólico sejam analisadas com um olhar crítico.

A Igreja Nossa Senhora do Carmo sofreu várias intervenções desde a chegada da Corte portuguesa à cidade do Rio de Janeiro. Em função destas sucessivas reconfigurações espaciais e de uso não foi possível à equipe de pesquisa histórica determinar com segurança a realidade física daquele espaço em 1808. Por isso, o foco dos estudos fixou-se no século XIX, por não haver 
informações documentais que relatassem o templo nos períodos anteriores, e construiu hipóteses sobre a arquitetura e os usos deste espaço. Imagina-se que a construção possuía uma configuração arquitetônica tão simples quanto o material e a técnica construtiva com a qual era feita, à semelhança das construções encontradas na colônia.

A pesquisa às fontes indica uma recorrente preocupação com o estado de conservação da igreja, que ao longo da primeira metade do século XIX foi alvo de "reclamações, pedidos, solicitações, relatos e avisos". ${ }^{25}$ Um exemplo é a constatação de que em 1830 a construção, apesar de sua notoriedade, possuía a torre sineira executada em madeira, o que, segundo o historiador Rodrigo Borges Monteiro,responsável pela pesquisa histórica da Igreja Nossa Senhora do Carmo, poderia indicar que este não foi um elemento privilegiado na adaptação que a igreja sofreu para se adequar ao seu novo status, ou ainda, que seu acabamento não era condizente com a importância da construção. Entretanto, em função da fragilidade do material, existia a preocupação das autoridades com o estado de conservação da torre, de tal forma que, em 1937, a torre foi substituída por outra, em alvenaria.

Outro ponto que suscitou questionamento diz respeito ao caminho que a Família Real realizava para chegar à então Capela Real. Registros indicam a existência de um corredor ligado à torre sineira de madeira, que serviria para os membros da Corte se deslocarem das suas residências - o Paço Real e o Convento dos Carmelitas - para a igreja, sem ter que sair à rua. Estaria então se tratando de localizar o acesso mais utilizado que a igreja possuía na época de D. João, pois através dele a nobreza acessava a igreja para liturgias rotineiras e eventos de menor importância.

Monteiro ainda ressalta que mesmo sendo um edifício de grande importância dentro da dinâmica da cidade, que se sobressaía por abrigar grandes celebrações, ele possuía uma precariedade construtiva que preocupava as autoridades da época. De modo similar ao que mostram as fontes históricas, a precariedade existia em 2006, ano em que foi firmado o contrato para a restauração da igreja.

Ela está registrada no Estudo preliminar para o restauro arquitetônico, desenvolvido pela empresa Velatura Restaurações Ltda, parceira da Fundação Roberto Marinho neste e em outros projetos coordenados pela instituição. Este documento, que faz parte do conjunto de registros técnicos gerados pelas empresas responsáveis pela execução das obras, contém um memorial descritivo, plantas arquitetônicas e documentos fotográficos do estado em que a igreja se encontrava antes das obras de restauração. Nesta fonte de pesquisa, os técnicos ressaltam duas preocupações principais: o estado do monumento em função da pouca ou nenhuma manutenção e as intervenções "pouco criteriosas" realizadas nas instalações. Tais intervenções, de intenção modernizante e feitas 
sem acompanhamento técnico, mostraram-se por vezes desastrosas. Foi o caso do incêndio ocorrido em 2005. Iniciado no nártex da igreja e ocasionado por um curto circuito, ele ocorreu concomitante às obras de restauração das fachadas da Rua Primeiro de Março e Rua Sete de Setembro que, através de um convênio realizado entre a Mitra Arquidiocesana e a Prefeitura do Rio de Janeiro, estavam em andamento desde 2004. A Mitra e a SAMAS vinham, desde 2002, firmando parcerias com o poder público, o Iphan e a iniciativa privada com o objetivo de promover obras que melhorassem o estado da construção. Porém, os projetos desenvolvidos até o convênio firmado em 2006 atendiam apenas parcialmente às necessidades da igreja.

A precariedade das instalações era uma preocupação dos atores sociais que vivenciavam o espaço e dele dependiam para a realização de suas atividades. Todos os depoimentos apontam a situação limítrofe da construção, que ameaçava a integridade física dos frequentadores.

[...] Então encontrei a antiga Sé, falando popular, caindo aos pedaços. Inclusive, o Ministério do Trabalho foi fazer logo uma fiscalização do ambiente de trabalho e apresentou vários pontos, até mesmo para os nossos funcionários trabalharem: iluminação, os assoalhos, todos cedendo e tudo mais; quanto mais para uma freqüência de missa, participação do povo e visitação. Então, encontrei a igreja, realmente, assim... (Padre Roque - Pároco da Igreja Nossa Senhora do Carmo da antiga Sé).

O impacto que a ausência de conservação trazia para os fiéis fez com que estes vissem no processo de restauração implantado em 2006 uma maneira de salvar a construção e perpetuar sua ligação com ela. Fica claro, porém, que durante os dezoito meses de obra os conflitos e dúvidas com relação ao futuro da igreja existiram. Foi preciso passar por um processo de intensa negociação para que, ao final, o resultado pudesse ser entendido como satisfatório por todos.

\section{PATRIMÔNIO EM DISPUTA}

A elaboração do projeto para a restauração da Igreja Nossa Senhora do Carmo também precisou levar em conta elementos que iam além da recuperação da construção. A igreja veio sofrendo transformações em sua decoração interna ao longo dos anos, de forma que se sobrepuseram uma série de estilos decorativos em seu interior. Coube ao Iphan a pesquisa que definiria o conceito a ser perseguir nos projetos. Segundo Mariângela Castro, esta estendeu-se de outubro de 2006 a março de 2007, momento do início das obras. 
A análise realizada pelo Iphan incluiu inúmeras prospecções que buscavam revelar as diversas transformações pelas quais a igreja havia passado durante sua história. A talha rococó, presente em toda a nave, transepto, capela-mor e capelas laterais é o elemento decorativo mais relevante da construção. Porém, também foram encontrados indícios da época em que houve marmorização de alguns trechos e de pintura em estêncil na capela-mor. Além disso, vale ressaltar que quando D. João VI chega ao Rio de Janeiro e transforma a igreja dos carmelitas em Capela Real, a talha de mestre Inácio Ferreira Pinto já estava executada, datada de 1785, não tendo, porém, recebido ainda a douração, que só ocorreu em 1817, quando do preparo da igreja para o casamento de D. Pedro com D. Leopoldina.

As escolhas feitas a propósito do recorte histórico que estaria evidenciado após a restauração foram extraídas de uma variada gama de possibilidades abertas pelas pesquisas. A definição de qual período retratar é determinante no processo, pois dela deriva o repertório específico de símbolos e significados posto em primeiro plano, ou seja, registrado nas paredes do templo, e o outro repertório esquecido, pelo menos por hora.

Optou-se por valorizar o que Mariângela Castro chamou, na entrevista que me concedeu, de período de "fausto" arquitetônico da igreja, a saber, o que abrange o governo de D. João VI e D. Pedro I. Identifica-se no discurso da entrevistada ter havido, dentro do campo técnico, uma disputa com relação a isso:

\footnotetext{
Eu acho que teve muita conversa, muita discussão. No primeiro momento, vamos voltar, mas... e aí? A gente não vai recuperar o estêncil? O Iphan queria que a capela-mor tivesse um momento mais moderno, vamos dizer assim, onde o estêncil e o granitizado aparecessem, e a nave não. Mas nós da Fundação fomos contra, porque a arquitetura, ela não serve para isso. Vamos deixar as janelas. Foi aí que a gente deixou as janelas estratigráficas (Arquiteta Mariângela Castro - Fundação Roberto Marinho).
}

Rememorar a época do Rio de Janeiro como local de moradia da Família Real através das talhas rococós de mestre Inácio, mesmo elas não sendo recuperadas à exatidão do que eram quando da chegada da Família Real, evidencia que a restauração do monumento estava atendendo a um propósito importante, de fazer da Igreja Nossa Senhora do Carmo da antiga Sé a construção símbolo da comemoração do bicentenário da vinda de D. João VI. Por certo, alternativas existiam dentro da proposta de restauração e, se postas em evidência, seriam tão justificáveis quanto os elementos destacados 
ao final das obras. Mas estas cumpriam um propósito simbólico específico que direcionava o percurso das escolhas e representações.

A utilização das janelas estratigráficas para revelar um elemento decorativo diferente daquele predominante no ambiente promoveu a convergência da orientação técnica com a mensagem simbólica. Temos, desdobradas sobre um mesmo espaço, duas mensagens: a primeira é a que nos remete a uma presença monárquica, com suas talhas douradas repousando sobre fundo bege, deixando claro o significado maior de um espaço cujo tempo e cuja memória são submetidos ao primado da história política. A segunda é a mensagem investigativa que, através de uma janela, nos mostra que a trajetória daquele lugar não se resumiu ao período monárquico. Ela foi além e o ressignificou, investindo-o da atualidade necessária à sua continuidade mutável no tempo.

Se a grande conexão entre a igreja e a chegada da Família Real fazse no seu interior, através dos elementos decorativos, o mesmo não ocorre do lado de fora da construção, onde a fachada lateral voltada para a rua Sete de Setembro, por exemplo, manteve o estilo eclético no qual foi construída entre o final do século XIX e início do XX. Essa fachada apresenta elementos predominantemente neo-renascentistas, "com um embasamento expressivo, com tratamento mais rústico, executado em argamassa imitando pedra, como se estivesse assentada uma sobre as outras, de forma simples e tradicional. Nos dois pavimentos superiores, o acabamento dos materiais vai se refinando, com $\mathrm{o}$ aparecimento de frisos boleados, balaustradas que marcam a modulação e o ritmo da fachada". ${ }^{26}$

A fachada principal, voltada para a rua Primeiro de Março, veio sofrendo alterações ao longo dos anos e sua última forma foi dada pelo Cardeal Arcoverde, que lhe atribuiu elementos ao gosto eclético. Mariângela Castro ressalta em sua entrevista que não se pensou em resgatar a fachada dos tempos de D. João VI, pois a atual se tornou muito expressiva e está associada ao imaginário da população: “[...] Ninguém em sã consciência demoliria tudo que o cardeal Arcoverde fez em prol da qualidade que aquela arquitetura tem, por quê? Porque essa intervenção do cardeal Arcoverde, ela já foi tão drástica, que ela passou a ser a nova fachada da igreja". O monumento passa a espelhar, então, dois momentos da história da igreja, mostrando a utilização de diferentes critérios para as escolhas técnicas, ainda que sem comprometer a leitura do monumento.

Entretanto, em alguns momentos, as decisões com relação a objetos e usos propostos para os lugares revelaram-se bastante conflituosos. Exemplo disso é a questão da destinação que se daria à sala onde hoje se encontra a pia batismal. No projeto arquitetônico inicial, aquela sala seria utilizada como loja para venda de artigos religiosos, permanecendo a pia batismal em frente 
à Capela São Pedro de Alcântara. Padre Roque afirma, na entrevista que me concedeu, que a pia havia sido deslocada para junto do altar depois de 1960, mas em consulta ao processo de tombamento da igreja ela apareceu originalmente na sala. Então, foi solicitada uma alteração no projeto desenvolvido pela Fundação Roberto Marinho para que a pia voltasse ao seu local original, mas, segundo Padre Roque, houve resistência a essa solicitação, sendo necessária a interferência do Bispo Auxiliar da Arquidiocese do Rio de Janeiro, Dom Edney Gouvêa Mattoso.

Outro exemplo, presente tanto no discurso da arquiteta Mariângela Castro quanto no do Padre Roque, diz respeito ao cadeiral ${ }^{27}$ existente na capela-mor, retirado durante as obras de restauração. Houve algum desconforto por parte da Mitra com relação a essa remoção, pois tal mobiliário representava a época em que a igreja foi sede do cabido. Sua presença, mesmo sendo incompatível com o recorte adotado, fazia referência a uma importante passagem histórica, quando a Igreja Nossa Senhora do Carmo tinha papel de destaque dentro do cenário religioso carioca. Após um longo período de diálogo optou-se pela retirada do cadeiral da capela-mor, mas ficou a garantia de que quando a Capela do Senhor dos Passos fosse restaurada, o cadeiral presente nela, mesmo não sendo original, permaneceria como um símbolo da presença do cabido.

Esses dois momentos relatados nas entrevistas mostram o quão polissêmico pode ser o bem patrimonial, alvo dos investimentos díspares de atores que a todo o momento colocam suas experiências e memórias em jogo. Esse esforço concentrado em torno da reconstrução dos signos do patrimônio edificado demonstra, junto com a necessidade de mediação entre memórias em disputa, a negociação entre a narrativa técnica e o imaginário social.

Buscando entender um pouco mais sobre essa variedade de discursos e memórias, volto o olhar para os paroquianos da Igreja Nossa Senhora do Carmo e para a maneira como este interagiram com o processo decisório das obras de restauração. Durante as entrevistas que realizei, pude perceber que apesar das obras possuírem como premissa básica o cunho pedagógico, a interlocução entre os técnicos e esses atores sociais foi, por vezes, falha e distante.

Todo o processo decisório sobre as obras de restauração envolveu a negociação direta entre o grupo técnico - formado pela Fundação Roberto Marinho, Iphan e Instituto de Arqueologia Brasileira - e a Mitra Arquidiocesana e a SAMAS. Os paroquianos eram informados das decisões através do Padre Roque, que desempenhou a função de interlocutor e mediador entre os grupos, pois a maioria das decisões impactava de maneira direta a rotina das celebrações e reuniões realizadas no templo.

A julgar pelos depoimentos, as obras geraram grande ansiedade entre os fiéis, que precisavam deslocar suas atividades sem compreender com clareza o direcionamento decisório que as ordenava. Além disso, os grupos paroquiais 
perderam espaços cativos dentro da igreja. Com o projeto de restauração ficaram estabelecidos novos usos para salas, altares e uma cozinha onde eram preparadas comidas servidas em festas da igreja. Isso gerou, além de desconforto, certa dose de resistência destes atores para com as intervenções arquitetônicas. A importância e a necessidade da intervenção estavam claras, pois as condições precárias da construção começavam a inviabilizar seu uso, mas a falta de comunicação entre quem concebeu o projeto e o usuário final era evidente.

O padre é que ficou encarregado disso [comunicar aos fiéis sobre as obras]. Mas só dizia para a gente: Sandra, vocês têm que esvaziar a sala; fulana, vocês têm que desocupar. A gente mudou daqui para lá, sabe, ficamos lá em cima numa salinha. (Dona Sandra - Grupo de Oração Pão da Palavra) Uma senhora falou: será que eu vivo até lá, para ver essa igreja? Então, algumas até choraram, quando a igreja foi reaberta. Porque elas acompanharam também, tivemos visita ao local em determinados períodos, para que vissem o passo a passo de cada etapa. Então as pessoas participaram disso. Eu fiz questão de colocar o capacete para poder visitar, a hora que fosse. Sabiam que iam perder alguns espaços por causa do sítio. Então, tudo isso tinha que ser explicado (Padre Roque - Pároco da Igreja Nossa Senhora do Carmo da antiga Sé).

Diante desta situação, torna-se válido questionar se houve o reconhecimento da importância deste grupo social por parte dos que conceberam o projeto. Quando se fala que a restauração do bem patrimonial é feita para a população, parece-me que a população se traduz em abstração, na medida em que os fiéis, grupo que maior proximidade tem com o bem cultural em questão, não possuem voz durante o processo. Como se a construção fosse preparada para uma situação futura e o seu presente, de alguma maneira, fosse descartado.

José Reginaldo Santos Gonçalves em seu artigo Ressonância, materialidade e subjetividade: as culturas como patrimônio, trata de um ponto do qual podemos nos apropriar para tornar mais clara a discussão sobre a importância da valorização do ponto de vista daqueles que experimentam diariamente o bem patrimonial.

As variações de significado nas representações sobre a categoria "patrimônio" oscilam possivelmente entre um patrimônio entendido como parte e extensão da experiência e, portanto do corpo, e um patrimônio entendido de modo 
objetificado, como coisa separada do corpo, como objetos a serem identificados, classificados, preservados, etc..$^{28}$

Buscar o ponto de equilíbrio entre essas duas maneiras de atribuir significado ao patrimônio talvez seja a forma de tornarmos a sua representação mais verdadeira dentro da realidade construída por esses grupos sociais, os quais interagem de maneira particular com a construção e vêem ali signos específicos a serem valorizados. Deixar de lado o "esforço obsessivo de objetificação ou naturalização dos patrimônios" ${ }^{29}$, tendo em vista que eles são constituídos por olhares em constante mutação talvez seja a melhor maneira de pensarmos as políticas públicas que se dedicam a esse tema.

\section{CONSIDERAÇÕES FINAIS}

A criação da identidade nacional através da legitimação da memória institucional relacionada ao objeto patrimonial deve ser vista com cautela, pois os signos postos em destaque foram indicados por agentes sociais detentores de conhecimentos especializados, que ali souberam identificar elementos históricos coerentes com a memória que se quer ter revelada. A análise do processo de restauração da Igreja Nossa Senhora do Carmo mostra que a interferência feita possui objetivos claros, orientados pela imagem desejada ao final das obras. Não havia, portanto, no caso desta igreja, a possibilidade de que o resultado final espelhasse outra época senão a do período joanino, pois este é que servia ao projeto de memória enquadrada pelo poder público.

A eleição do repertório simbólico que irá compor a memória nacional tem, como um de seus objetivos, o incentivo à noção de pertencimento que religa sociedade, Estado e território. Entretanto, essa ligação deve ser baseada em um diálogo eficaz entre quem constrói o discurso e quem o recebe para que se estabeleça um elo simbólico entre os atores e a memória eleita. A "ressonância" ${ }^{30}$ do discurso materializado pelo bem patrimonial junto aos atores sociais é determinante para a eficiência do projeto proposto para a memória e o reforço ao pertencimento nacional.

E por fim, remetendo-me outra vez à Canclini, destaco a importância de assumida pelos estudos críticos sobre políticas de salvaguarda ao patrimônio. Estudos que levem em consideração a percepção dos usuários do espaço, que estabelecem com ele relações que muitas vezes fogem àquelas imaginadas pelos representantes do saber e do Estado. Esse ponto de vista possibilita um entendimento mais profundo sobre a problemática da difusão, percepção e compreensão do bem patrimonial, ajudando no desenvolvimento de práticas 
efetivas de educação, preservação e desenvolvimento do patrimônio. Desta maneira, caminharemos no sentido de viabilizar a democratização da cultura e tornar real a apropriação do nosso patrimônio pela sociedade.

\section{NOTAS}

${ }^{1}$ Este trabalho é uma adaptação de parte da dissertação de mestrado profissional da autora, intitulada "Olhares sobre a restauração da Igreja Nossa Senhora do Carmo da antiga Sé". Rio de Janeiro: Programa de Pós Graduação de História, Política e Bens Culturais (PPHPBC), Centro de Pesquisa e Documentação de História Contemporânea do Brasil (CPDOC) da Fundação Getulio Vargas, 2010.

2 "O convênio entre a Fundação Roberto Marinho e a Prefeitura da Cidade do Rio de Janeiro foi assinado no dia 11 de agosto de 2006. Nesta ocasião, também foi assinado um convênio de cooperação técnica com a Mitra Arquidiocesana e o Instituto do Patrimônio Histórico e Artístico Nacional - IPHAN." FUNDAÇÃO ROBERTO MARINHO. Release Geral. Rio de Janeiro, 2008.

3 POLLAK, Michael. "Memória, Esquecimento, Silêncio". Estudos Históricos, Rio de Janeiro, vol. 2, n. 3, 1989, p. 3-15.

${ }^{4}$ Disponível em: http://www.rio.rj.gov.br/sedrepahc/ Acesso em: 21 set. 2009.

${ }^{5}$ O projeto, orçado em R \$ 11,5 milhões, envolveu o restauro artístico do interior e das fachadas da igreja e a realização de obras de infra-estrutura, além da implementação de ações que além do seu caráter educativo e de documentação, irão garantir recursos para a auto-sustentabilidade do templo: um espetáculo de "Som e Luz", programa de capacitação de professores e visitas guiadas de alunos de escolas públicas e privadas ao canteiro de restauração; criação de vídeo e publicações educativas; implantação de exposições. Disponível em: http://www.rio.rj.gov. br Acesso em: 25 set. 2009.

${ }^{6}$ GONÇALVES, José Reginaldo Santos. "Ressonância, materialidade e subjetividade: as culturas como patrimônio". In: Horizontes Antropológicos. Porto Alegre, ano 11, n. 23, jan/ jun 2005. p. 15-36.

${ }^{7}$ Foram entrevistadas nove pessoas, entre junho a agosto de 2009. Diretamente ligados à paróquia estão o Pe. Roque e fiéis da confraria N. Sra da Cabeça e do grupo de oração Pão da Palavra. Cada um dos três roteiros de entrevistas procuraram cobrir a atuação (diversa) de cada um dos grupos envolvidos com o processo de restauração. O primeiro roteiro foi elaborado para as entrevistas com os paroquianos e funcionários da igreja. Tinha por objetivo entender a relação do entrevistado com a igreja e sua história dentro daquele espaço. Além disso, o roteiro possibilitava uma comparação entre o momento que antecedeu a restauração, o período das obras e como estava sendo a retomada das atividades cotidianas após a reabertura. O segundo e terceiro roteiros, direcionados, respectivamente, à arquiteta Mariângela Castro, gerente de projetos da Fundação Roberto Marinho e ao Padre Roque, pároco da igreja desde 2005, focavam as escolhas técnicas e a mediação política dos conflitos entre os diferentes grupos durante as obras. No roteiro direcionado ao Padre Roque também há a exploração mais detalhada sobre o gerenciamento da igreja após sua abertura, bem como os benefícios e dificuldades de 
advieram das obras. Tenho que salientar também o grande apoio dado pela Fundação Roberto Marinho, na figura da arquiteta Mariângela Castro, que além de me conceder uma belíssima entrevista, proporcionou-me o contato com a documentação textual e fotográfica gerada para e pelas obras de restauração.

8 "Por ressonância eu quero me referir ao poder de um objeto exposto atingir um universo mais amplo, para além de suas fronteiras formais, o poder de evocar no expectador as forças culturais complexas e dinâmicas das quais ele emergiu e das quais ele é, para o expectador, o representante." (Greenblatt, citado em Gonçalves, op. cit., grifo do autor, tradução minha).

9 CANCLINI, Néstor G. "O Patrimônio Cultural e a Construção Imaginária do Nacional”. Revista do Patrimônio Histórico e Artístico Nacional, no. 23, 1994. p. 94-115.

${ }^{10}$ NORA, Pierre. "Entre memória e história. A problemática dos lugares."Projeto História, São Paulo, n. 10, 1993.

${ }^{11}$ NORA, op. cit., p. 9.

${ }^{12}$ ROUSSO, Henry. “A Memória não é mais o que Era”. In: AMADO, Janaína A. \& FERREIRA, Marieta de M. Usos e abusos da História Oral. Rio de Janeiro: Ed. FGV, 1998. p. $93-130$.

${ }^{13}$ CASTRO, Mariângela; LODI, Cristina. "A restauração do monumento-símbolo das comemorações dos 200 anos da chegada de D. João e da Família Real ao Rio de Janeiro". In: Castro, Mariângela (Coord.). Igreja de Nossa Senhora do Carmo da Antiga Sé: história e restauração. São Paulo: Companhia Editora Nacional, 2008. p. 141.

${ }^{14}$ Ibidem.

${ }^{15}$ A arquiteta Mariângela Castro é carioca, nascida em 09 de dezembro de 1955. Trabalha na Fundação Roberto Marinho desde 1985, ocupando hoje o cargo de Gerente de patrimônio. Neste período já atuou em diversos projetos, nos quais destacam-se: a restauração da Igreja da Lapa dos Mercadores no Rio de Janeiro, a recuperação da Biblioteca Nacional no Rio de Janeiro, a recuperação do pátio interno do Museus Nacional de Belas Artes no Rio de Janeiro, o projeto de revitalização do Parque Ibirapuera de São Paulo, a recuperação do Jardim Botânico do Rio de Janeiro, o restauro da Igreja da Pampulha em Belo Horizonte, a implantação do Memorial do Rio Grande do Sul, a execução do Anfiteatro Por do Sol em Porto Alegre, a revitalização do Museu Náutico de Rio Grande, a implantação do "Som e Luz" na Igreja de S. Francisco da Ordem III em Salvador, a implantação do Museu do Descobrimento de Porto Seguro, o projeto de implantação de escadas rolantes e elevadores no Cristo Redentor, o projeto Memória do Movimento Estudantil, e, atualmente, a implantação do Paço Frevo em Recife que começará em janeiro de 2010. Foi coordenadora do livro Igreja Nossa Senhora da antiga Sé: história e restauração, lançado em janeiro de 2009 , e que trata da restauração da igreja realizada para as comemorações do bicentenário de chegada da Família Real ao Rio de Janeiro. Mariângela Castro me concedeu entrevista temática sobre o processo de restauração da Igreja Nossa Senhora do Carmo, do qual foi coordenadora, no dia 27 de junho de 2009, em seu apartamento na Lagoa, zona sul da cidade do Rio de Janeiro.

${ }^{16} \mathrm{O}$ Padre Roque Costa Souza está à frente da paróquia da Igreja de Nossa Senhora do Carmo da antiga Sé desde 2005. Iniciou sua trajetória dentro da Igreja Católica aos 18 anos, já com a intenção de se tornar padre diocesano. Antes de assumir a Igreja Nossa Senhora do Carmo passou, no bairro de Anchieta no Rio de Janeiro, por duas paróquias: Igreja do Bom Pastor e São Francisco de Assis, onde foi formador do seminário durante quatro anos. Depois desses quatro anos foi para o bairro de Realengo, assumindo a paróquia de Nossa Senhora das 
Graças e São João Batista, onde permaneceu por seis anos. Hoje, além da paróquia de Nossa Senhora do Carmo, Padre Roque é o capelão do Quartel da Polícia Militar do Estado do Rio de Janeiro (PMERJ). Foi neste local que, no dia 08 de setembro de 2009, o pároco me concedeu entrevista temática sobre sua vivência dentro desta paróquia antes, durante e depois das obras de restauração.

${ }^{17}$ CASTRO; LODI, op. cit., p. 145.

${ }^{18}$ Dona Joana D`arc Marinho é aposentada, mora no bairro de Vila Isabel, zona norte carioca, e tem 66 anos. Sua trajetória relacionada a paróquia de Nossa Senhora do Carmo se inicia em 1991, através do grupo de oração Pão da Palavra e se aprofunda em 1996 quando passa a ser secretária da igreja, função que exerceu até 2001. Dona Joana frequenta o local todas as segundas-feiras, por ser a responsável pela catequese de adultos, além de fazer a pregação no grupo de oração uma vez por mês. No dia 06 de julho de 2009, Dona Joana me concedeu entrevista temática, na sacristia da Igreja Nossa Senhora do Carmo, sobre sua vivência dentro desta paróquia antes, durante e depois das obras de restauração.

${ }^{19}$ Dona Ondina Gomes dos Santos Souza é aposentada, mora no bairro do Méier, zona norte carioca, e tem 83 anos. Começou a frequentar a igreja em 1974, em função de uma promessa que fez a Nossa Senhora da Cabeça e deste então está presente neste local todas as quartasfeiras, às 9 horas da manhã para a missa da Confraria. Dona Ondina hoje exerce, pela terceira vez, o cargo de presidente da Confraria. No dia 24 de junho de 2009, na sacristia da Igreja Nossa Senhora do Carmo, me concedeu entrevista temática sobre sua vivência dentro desta paróquia antes, durante e depois das obras de restauração.

${ }^{20}$ Dona Sandra é aposentada, mora no bairro da Cidade Nova, centro do Rio de Janeiro, e tem 57 anos. Começou a frequentar a paróquia de Nossa Senhora do Carmo em 1990, com a esperança de encontrar conforto, pois passava por momentos difíceis em sua vida pessoal. Desde o início está ligada ao Grupo de Oração Pão da Palavra, do qual é hoje coordenadora, e busca nos projetos de assistência social - visitas a hospitais, asilos e etc.- reforçar a prática religiosa. No dia 30 de junho de 2009, na sacristia da Igreja Nossa Senhora do Carmo, me concedeu entrevista temática sobre sua vivência dentro desta paróquia antes, durante e depois das obras de restauração.

${ }^{21}$ Os funcionários entrevistados foram: Darlan Mendes Matheus (entrevista realizada no dia 24 de junho de 2009) - Darlan, além de auxiliar o Padre Roque nas missas, como coroinha, realiza diversos serviços na igreja como: segurança, operador de áudio e luz em casamentos, serviços administrativos e etc.. Mora em Realengo, na zona oeste da cidade, tem 22 anos. Trabalha na igreja desde 2006, quando foi convidado pelo Padre Roque para auxiliá-lo nas missas. Valéria Schuenk (entrevista realizada no dia 27 de julho de 2009) - Valéria ocupa, desde o ano de 2004, a posição de secretária da igreja, substituindo Dona Joana D`arc que até o referido ano exercia essa função. É responsável por todo o serviço administrativo da paróquia o que inclui agendamento de casamentos, missas, registros e arquivamentos. Além disso, presta atendimentos ao público que hoje procura a igreja como ponto turístico. Já havia trabalhado como secretária em outra paróquia no bairro de Oswaldo Cruz, zona norte da cidade. Mora na zona oeste da cidade. José Luiz da Silva (entrevista realizada no dia 10 de julho de 2009) - José tem 29 anos e é auxiliar de serviços gerais e administrativos. Este funcionário está na igreja desde 2003 e se diferencia dos demais por morar neste espaço. Ele esteve presente em todos os momentos da restauração, sendo uma de suas funções auxiliar o grupo técnico no que fosse possível.

${ }^{22}$ CHOAY, Françoise. Alegoria do Patrimônio. São Paulo: Unesp, 2008. p. 250. 
${ }^{23}$ CASTRO; LODI, op. cit., p. 143.

${ }^{24}$ A "Carta de Burra" é uma carta patrimonial gerada pelo Conselho Internacional de Monumentos em Sítios, realizado na Austrália em 1980.

${ }^{25}$ MONTEIRO, Rodrigo Borges. "A história da Igreja do Carmo: faces do império: a Capela Imperial e suas transformações ao longo do século XIX". In: CASTRO, Mariângela (Coord.). Igreja de Nossa Senhora do Carmo da Antiga Sé: história e restauração. São Paulo: Companhia Editora Nacional, 2008. p. 153.

${ }^{26}$ CALDAS, Wallace. "Fachadas”. In: CASTRO, Mariângela (Coord.). Igreja de Nossa Senhora do Carmo da Antiga Sé: história e restauração. São Paulo: Companhia Editora Nacional, 2008. p. 161.

${ }^{27}$ Conjunto de cadeiras com espaldares mais altos que se localizam próximo na capela-mor das igrejas e são ocupadas pelos integrantes do clero.

${ }^{28}$ GONÇALVES, op. cit., p. 32.

${ }^{29}$ Idem. Ibidem.

${ }^{30} \mathrm{Idem}$. 